\title{
Article \\ Breakpoint Analysis for the COVID-19 Pandemic and Its Effect on the Stock Markets
}

\author{
Karime Chahuán-Jiménez ${ }^{1}\left(\mathbb{D}\right.$, Rolando Rubilar ${ }^{2} \mathbb{D}$, Hanns de la Fuente-Mella ${ }^{3} \mathbb{D}$ and Víctor Leiva ${ }^{4, *}$ \\ 1 Escuela de Auditoría, Centro de Investigación en Negocios y Gestión Empresarial, \\ Facultad de Ciencias Económicas y Administrativas, Universidad de Valparaíso, Valparaíso 2362735, Chile; \\ karime.chahuan@uv.cl \\ 2 Instituto de Estadística, Facultad de Ciencias, Universidad de Valparaíso, Valparaíso 2360102, Chile; \\ rolando.rubilar@uv.cl \\ 3 Escuela de Comercio, Facultad de Ciencias Económicas y Administrativas, Pontificia Universidad Católica de \\ Valparaíso, Valparaíso 2340031, Chile; hanns.delafuente@pucv.cl \\ 4 Escuela de Ingeniería Industrial, Facultad de Ingeniería, Pontificia Universidad Católica de Valparaíso, \\ Valparaíso 2362807, Chile \\ * Correspondence: victor.leiva@pucv.cl or victorleivasanchez@gmail.com
}

Citation: Chahuán-Jiménez, K.;

Rubilar, R.; de la Fuente-Mella, H.; Leiva, V. Breakpoint Analysis for the COVID-19 Pandemic and Its Effect on the Stock Markets. Entropy 2021, 23, 100. https://doi.org/10.3390/ e23010100

Received: 13 December 2020 Accepted: 8 January 2021 Published: 12 January 2021

Publisher's Note: MDPI stays neutral with regard to jurisdictional clai$\mathrm{ms}$ in published maps and institutional affiliations.

Copyright: (C) 2021 by the authors. Licensee MDPI, Basel, Switzerland. This article is an open access article distributed under the terms and conditions of the Creative Commons Attribution (CC BY) license (https:// creativecommons.org/licenses/by/ $4.0 /)$.

\begin{abstract}
In this research, statistical models are formulated to study the effect of the health crisis arising from COVID-19 in global markets. Breakpoints in the price series of stock indexes are considered. Such indexes are used as an approximation of the stock markets in different countries, taking into account that they are indicative of these markets because of their composition. The main results obtained in this investigation highlight that countries with better institutional and economic conditions are less affected by the pandemic. In addition, the effect of the health index in the models is associated with their non-significant parameters. This is due to that the health index used in the modeling would not determine the different capacities of the countries analyzed to respond efficiently to the pandemic effect. Therefore, the contagion is the preponderant factor when analyzing the structural breakdown that occurred in the world economy.
\end{abstract}

Keywords: data science; econometric models; financial contagion and crisis; statistical modeling

\section{Introduction}

From a financial point of view, the available data with respect to the effects of health pandemics on global market are limited [1]. The financial contagion provides evidence of self-excitation in both the United States (US) and other world markets as well as of asymmetric cross-excitation [2]. Thus, the US market generally has more influence on the jump intensity from other markets than vice versa.

Outbreaks of infectious diseases, such as SARS, attract substantial attention from a health perspective [3]. In addition, there is awareness that their economic impact can be potentially high. However, the precise mechanism of how this impact occurs is unclear.

Global trade is a mechanism through which geographically distant epidemics could affect the countries. In terms of infectious diseases, some studies have found that epidemics can interfere with short-term economic results by changing expectations and deterring investment. Nevertheless, a link between epidemics and long-term growth has not been established [4]. A study indicates that US exports and the jobs supported by such exports were negatively affected by the 2014 Ebola outbreak in West Africa [4].

Extreme events have negative multidimensional impacts on health from the economic and social point of view, particularly at the macroeconomic level [5]. Some authors [6] mentioned that econometric models allow the estimation of probable costs and benefits of a pandemic.

The immediate economic costs of epidemics in affected regions can be considerable and are therefore frequently evaluated after notable outbreaks [4]. According to [7], the 
risk of COVID-19 is perceived differently over time and represents the probability of being viewed as an economic crisis. This study [7] offered several important implications and endorsements for policy makers and for asset managers as the COVID-19 pandemic outbreak continues its tremendous spread in the US, causing unprecedented volatility effects on the market [8]. A country affected by a pandemic-level infection with a betterorganized producer has a greater possibility of being in a better position to avoid a decrease in production $[9,10]$. In addition, we must mention the negative impact of COVID-19 on the financial markets, which is more marked than its positive impact. This stylized fact, also known as volatility asymmetry, has been modeled in $[11,12]$ by means of the volatility feedback effect.

Financial markets experience crises differently, regardless of whether these crises are contagious or not. However, after the crises, appropriate models for describing unusual events leading to such crises have become essential in the fields of finance and risk management $[13,14]$. The literature has related global financial crises with the concepts of interconnection, contagion, and spillover effects in markets [8].

Economic expectative suggests that, when two economies are well integrated through trade, investment, and financial relationships [15], a crisis in one economy is likely to quickly spread to the other one. This because exposure to financial globalization can lead to a higher vulnerability to a financial crisis, associating them with the concept of contagion effect. The capital benefit is greater in developing markets than in developed stock markets due to investing in emerging markets tends to be riskier [16].

Different effects have been identified on volatility in the short, medium, and long terms [17]. Impacts of the factors that contribute to contagion effects of volatility have no systematic patterns. Nevertheless, if the country is the transmitter or receiver of volatility, spillovers could be a potential reason, but the interdependence of the global stock markets highly reduces the risk avoidance benefits of investing in multiple stock markets. Furthermore, a clear understanding of intensity and variations in the transmission of volatility among markets could be crucial for international risk management in terms of global coverage strategies and asset allocation decision-making. Some authors [18] mentioned that volatility with respect to financial products could measure the fluctuations of a financial security price around its expected value. Investment decisions in financial markets strongly depend on expectations regarding expected returns and asset volatility.

The literature basically distinguishes three mechanisms through which economic disturbances spread among countries [19-22]. The first mechanism corresponds to the global shocks that affect all or almost all of the countries of the world. The transmission of shocks among countries translates into increases in correlation beyond any fundamental link, which is known as excess joint movement. The second mechanism corresponds to shocks from related countries, a phenomenon that has been referred to as foundation-based contagion. The third mechanism corresponds to the contagion, which is defined as a residual element, and therefore it is related to the extent and magnitude of the international transmission of crises [23].

The transition from the calm to the turbulent regime is driven by changes in the global jump risk [23]. This suggests that the contagion of the global financial market significantly affects the price of sovereign credit risk. Therefore, neglecting financial contagion and feedback effects of sovereign credit risk on national economic and financial developments lead to spurious results with respect to the determinants of sovereign country default spreads (CDS). Regression models of CDS on variables that capture the fundamental macroeconomic determinants of this spread can be formulated [24].

The financial contagion is modeled as an equilibrium phenomenon given that liquidity preference shocks are imperfectly correlated between regions. In the face of this type of financial effect, policy makers, investors, and researchers have raised the questions of why this phenomenon occurs and what can be done to mitigate the risk of contagious crises in the future $[25,26]$. Failure to consider financial contagion and country risk, measured 
through sovereign CDS [23], could generate a national economic and financial evolution with spurious results depending on the determinants of sovereign CDS.

Separating contagion from globalization is econometrically difficult $[15,27]$. According to [20], a contagion grows significantly in the links among markets after a shock in a country (or a group of countries). A number of authors [20,28] pointed out that (i) if two stock markets exhibit a high level of co-movement [29]; or (ii) if a particular index increases and another index also increases; or (iii) if a particular index decreases and another index also decreases during lulls, then a high correlation after a shock in one of the markets suggests interdependence, whereas a contagion is present only in the case of a significant increase in co-movement.

Complementing what was mentioned earlier, we can add that markets are strongly interconnected, losses spread through them, and financial contagion is magnified [30]. This is because the fears of adverse market shocks tend to spread among investors, generating panic behavior [31]. Financial stress grows significantly driven by stock market volatility, high liquidity premiums, and contagion risks [32]. This finding is supported by [31], where emerging market shocks have statistically and economically significant impacts on global equity markets. Such a fact confirms the assumption of the initial systemic importance of emerging market economies as drivers of global asset price developments. Moreover, for a negative shock in a market, the probability of negative shocks in other markets increases [30].

The objective of this research is to statistically evaluate the financial effect generated by the health crisis derived from the COVID-19 pandemic on the performance of the economies belonging or not to the Organization for Economic Co-operation and Development (OECD). A statistical analysis of structural breakdown is conducted, considering the main stock market indexes by country, health index, and country risk. In addition, this research considers, from the financial point of view, a review of the literature associated with economic crises, development methodology, results, discussion, and conclusions.

The rest of the paper is organized as follows. In Section 2, the statistical model is formulated together with the methodology to be used. Furthermore, in this section, the stock indexes utilized are defined. Section 3 reports the results obtained from our investigation mentioning some indications and recommendations. In Section 4, we provide the conclusions, discussions, limitations, and further research of this study.

\section{Modeling and Methodology}

Models of structural breakdown associated with stock market indexes are widely used in the literature $[31,33]$. In addition, models that incorporate external effects, such as shock events, being them the main cause of the volatilities of the markets, have been also studied [30,32]. In order to carry out the statistical modeling, first, the structural breakdown in time series associated with the stock market indexes are calculated. This breakdown is assumed as a consequence of the measures taken by the different countries to control the mentioned shock events. These measures can affect the stock market value of the companies belonging to the different indexes. Then, the change in the level suffered by each stock index is measured and, with these measurements, regression models are formulated allowing us to define the impact of various factors on the structural change of economies $[24,34,35]$.

In this research, world stock market indexes are used to evaluate the evolution and performance of the economies of different countries during the periods both before and after the declaration of the global health crisis produced by the spread of COVID-19 [33,36], which can be considered as a shock event. As an example of structural breakdown associated with stock market indexes, Figure 1 shows the evolution of the S\&P500 index, in which a structural breakdown in its price can be observed during the second week of March 2020. 


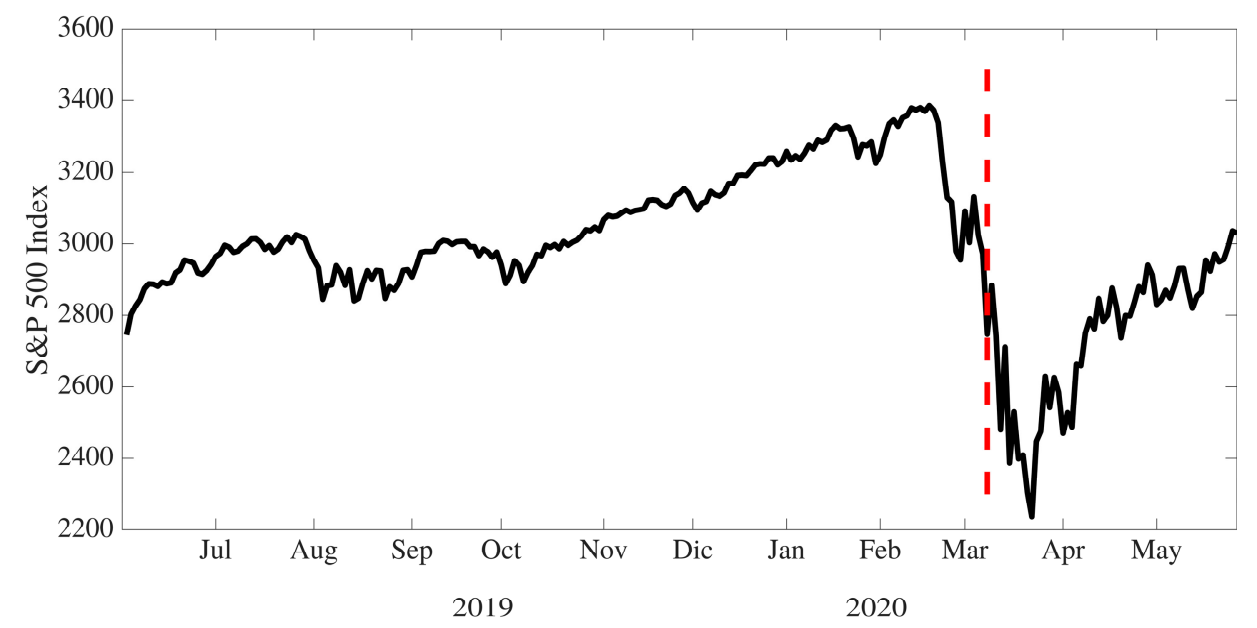

Figure 1. S\&P500 price evolution from 1 June 2019 to 30 May 2020. The vertical line in red corresponds to the estimated date of structural breakdown (9 March 2020).

The data used in the present study were obtained from Bloomberg at: https://bba. bloomberg.net/?utm_source=bloomberg-menu\&utm_medium=bcom and from the GHS index at: https:/ / www.ghsindex.org/wp-content/uploads/2019/10/2019-Global-HealthSecurity-Index.pdf. Data collection was made directly by each country for all of the series from the above-mentioned links. The indexes incorporated in this research are those that have the highest capitalization and volume in their markets. These indexes are the most traded and therefore the most liquid, allowing them to be representative of the entire analyzed universe [18]. The stock indexes considered here are based on daily observations of each time series; see Table 1. In this table, we describe the countries to be considered in the present study and their respective stock indexes. These countries (and their acronyms in parenthesis, when it corresponds) are Australia, Belgium, Brazil, Bulgaria, Canada, Chile, China, Colombia, Croatia, Cyprus, Egypt, Finland, France, Germany, Hungary, Iceland, India, Indonesia (IN), Iraq, Israel, Italy, Japan, Mexico, Malaysia, Nigeria, Norway, New Zealand (NZ), Pakistan, Peru, Philippines, Poland, Portugal, Qatar, Romania, Russia, Saudi Arabia (SA), Serbia, Slovakia, South Korea (SK), Spain, Sri Lanka (SL), Sweden, Switzerland (SW), Thailand, Turkey, Ukraine, United Kingdom (UK), and US. Within these countries, we consider cases with quite heavily COVID-19 hits, which is useful for our investigation.

Table 1. Stock index by country used in the study ( ${ }^{*}$ EN: Euronext; ${ }^{* *}$ MT: Msci Tadawul).

\begin{tabular}{cccccccc}
\hline Country & Index & Country & Index & Country & Index & Country & Index \\
\hline Australia & Asx 200 & France & $*$ EN 100 & Nigeria & Nse 30 & Serbia & Belex 15 \\
Belgium & Bel 20 & Germany & Dax & Norway & Oseax & Slovakia & Sax \\
Brazil & Ibov & Hungary & Bux & NZ & Nzx 50 & SK & Kospi 50 \\
Bulgaria & Sofix & Italy & Ftse Mib & Pakistan & Kse 100 & Spain & Ibex \\
Canada & Tsx & India & Nifty 50 & Peru & Igbvl & SL & Cse \\
Chile & Ipsa & IN & Jci & Philippines & Psei & Sweden & Omx 30 \\
China & Shanghai & Irak & Isx & Poland & Wig 30 & SW & Smi \\
Colombia & Colcap & Iceland & Icexi & Portugal & Psi 20 & Thailand & Set \\
Croatia & Crobex & Israel & Ta 100 & Qatar & Qe & Turkey & Xu 100 \\
Cyprus & Cymain & Japan & Nikkei 225 & Romania & Bet & Ukraine & Pfts \\
Egypt & Egx 70 & Malaysia & Fbm Klci & Russia & Moex & UK & Ftse 100 \\
Finland & Hex 25 & Mexico & Mexbol & SA & $* *$ MT 30 & US & S\&P500 \\
\hline
\end{tabular}

By using the data collected for the stock indexes defined in Table 1 , and based on the models supported by the background $[30-33,36]$, we state a functional relation defined as

$$
Y_{i}=f\left(x_{1 i}, x_{2 i}, x_{3 i}, x_{4 i}, x_{5 i}\right),
$$


where $Y_{i}$ is the effect of the structural breakdown in country $i ; x_{1 i}=f_{1}\left(\right.$ Health $\left._{i}\right)$ is the value of $X_{1}$ related to the health security of country $i$ measured by the global health security (GHS) index for 2019 [37]; $x_{2 i}=f_{2}\left(\operatorname{Risk}_{i}\right)$ is the value of $X_{2}$; and $x_{3 i}=f_{3}\left(\right.$ StdRisk $\left._{i}\right)$ is the value of $X_{3}$, both of them associated with the average risk value and its standard deviation for country $i$, respectively; and two control variables $x_{4 i}=f_{4}\left(\mathrm{OECD}_{i}\right)$ is the value of $X_{4}$, an indicator of whether or not country $i$ belongs to the OECD group; as well as $x_{5 i}=f_{5}\left(\mathrm{GDP}_{i}\right)$ is the value of $X_{5}$, which is linked to the gross domestic product (GDP) of country $i$ [35]. Note that the response variable $Y$ is measured as a percentage of the variation in the index between the average of the last three months (Diff3M), or six months (Diff6M), before the structural change and the value of the index as an average after two month of this change-which represents a loss of wealth of the countries present in this study; whereas Health represents a benchmarking of the health security of 195 countries [37].

We consider the period between July 2019 and May 2020 of the CDS on government bonds from execution to five years, provided by the Bloomberg database before mentioned.

Although CDS premiums do not capture exact default risk, the literature has documented that they are considered reliable and among the best default risk measures available [38]. Additionally, the CDS is used in [39] for risk analysis and as bond spreads because they are positively correlated with risk premium measures. However, the CDS show a higher correlation with country-specific credit risk drivers.

Based on Equation (1), the moment in which the structural breakdown of the series of indexes occurs for the different countries must be determined. In order to do this determination, the Wald test is used. This test consists of evaluating changes in the coefficients of a regression model during the periods defined by an unknown breakdown date, combined with the test statistics calculated for each possible breakdown date in the sample $[40,41]$. As mentioned, the period included for the analysis of each time series, described in Table 1, corresponds to 1 July 2019 until 28 May 2020. In this period, we work with 234 observations for 48 countries and indexes detailed in Table 2, which provides the estimated dates of structural breakdown using the Wald test.

Table 2. Structural breakdown date estimated by the Wald test for the indicated country.

\begin{tabular}{cccccccc}
\hline Country & Date & Country & Date & Country & Date & Country & Date \\
\hline Australia & $03 / 09 / 20$ & France & $03 / 09 / 20$ & Nigeria & $03 / 11 / 20$ & Serbia & $03 / 12 / 20$ \\
Belgium & $03 / 09 / 20$ & Germany & $03 / 09 / 20$ & Norway & $03 / 09 / 20$ & Slovakia & $03 / 17 / 20$ \\
Brazil & $03 / 04 / 20$ & Hungary & $03 / 09 / 20$ & NZ & $03 / 12 / 20$ & SK & $03 / 12 / 20$ \\
Bulgaria & $03 / 09 / 20$ & Italy & $03 / 09 / 20$ & Pakistan & $03 / 16 / 20$ & Spain & $03 / 09 / 20$ \\
Canada & $03 / 09 / 20$ & India & $03 / 12 / 20$ & Peru & $03 / 12 / 20$ & SL & $01 / 31 / 20$ \\
Chile & $03 / 13 / 20$ & IN & $03 / 09 / 20$ & Philippines & $03 / 09 / 20$ & Sweden & $03 / 09 / 20$ \\
China & $03 / 16 / 20$ & Iraq & $12 / 18 / 19$ & Poland & $03 / 09 / 20$ & SW & $03 / 06 / 20$ \\
Colombia & $03 / 09 / 20$ & Iceland & $03 / 06 / 20$ & Portugal & $03 / 09 / 20$ & Thailand & $03 / 09 / 20$ \\
Cyprus & $03 / 09 / 20$ & Israel & $03 / 09 / 20$ & Qatar & $03 / 02 / 20$ & Turkey & $03 / 09 / 20$ \\
Croatia & $03 / 09 / 20$ & Japan & $03 / 06 / 20$ & Romania & $03 / 09 / 20$ & Ukraine & $02 / 10 / 20$ \\
Egypt & $03 / 16 / 20$ & Malaysia & $03 / 06 / 20$ & Russia & $03 / 10 / 20$ & UK & $03 / 09 / 20$ \\
Finland & $03 / 09 / 20$ & Mexico & $03 / 09 / 20$ & SA & $03 / 09 / 20$ & US & $03 / 09 / 20$ \\
\hline
\end{tabular}

From Table 2, note that the entire estimated structural breakdown corresponds to dates prior to 17 March 2020. However, there are three countries that appear atypical to this phenomenon, which are Iraq, SL, and Ukraine. Therefore, their structural breakdown can be caused due to a phenomenon other than the one studied in this paper [18].

According to [30], a negative shock in one market increases the probability of negative shocks in other markets. Methodologically, it is considered that when a disturbance occurs in one index, it is reflected in the modified dynamics of the other indexes [42,43]. The existence of a structural breakdown implies that the behaviour of the time series changes. Moreover, for all countries within this investigation, the null hypothesis of the non-existence of a structural breakdown is rejected, and the difference in the average of the index value is as previously described. The main descriptive statistics of the variables 
considered in the functional formulation defined in (1) are reported in Table 3, whereas the linear relationships between the studied variables are reported in Figure 2. In this figure, the upper triangular sector corresponds to the Pearson correlation of the indicated variables; the lower triangular part corresponds to the scatter plots between these variables; and the diagonal corresponds to the histogram of such variables.

Table 3. Descriptive statistics of the variables considered in the model.

\begin{tabular}{ccccc}
\hline Variable & Minimum & Maximum & Mean & Standard Deviation \\
\hline Health & 25.80 & 83.50 & 54.87 & 13.22 \\
Risk & $11,037.89$ & $462,453.50$ & $106,106.13$ & $130,742.35$ \\
StdRisk & 505.46 & $54,134.31$ & $10,521.88$ & $12,775.89$ \\
Diff3M & 1.87 & 34.23 & 16.67 & 7.69 \\
Diff6M & 0.47 & 33.96 & 18.34 & 7.44 \\
\hline
\end{tabular}

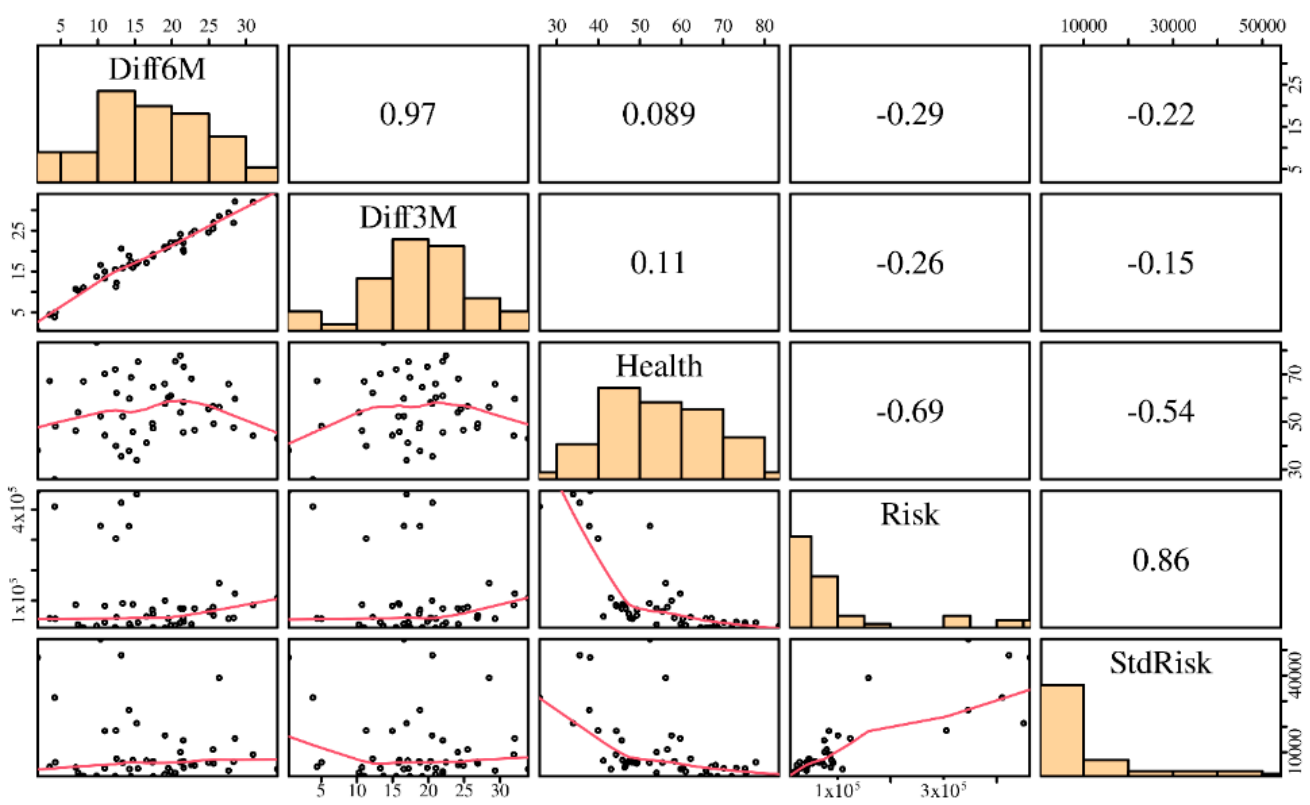

Figure 2. Descriptive summary of the variables studied.

From Figure 2, we detect adequate levels of correlation among the responses Diff3M and Diff6M with the covariates Health, Risk, and StdRisk, justifying the use of multiple linear regression models. However, when observing the correlations between the covariates Health, Risk, StdRisk, we assess a possible multicollinearity problem, which must be analyzed by means of the variance inflation factor (VIF). Its values for each estimated coefficient when modeling Diff3M are: $\operatorname{VIF}($ Health $)=1.93, \operatorname{VIF}($ Risk $)=5.27$, and $\operatorname{VIF}($ StdRisk $)$ $=3.91$, whereas when modeling Diff6M, similar values are obtained. Note that all of the VIF values are less than 10, indicating no collinearity problems; see details about the VIF and the used criterion in [44].

In order to perform the estimation of the regression model parameters based on the functional formulation defined in (1), we establish statistical models for the response variable $Y$ (Diff3M or Diff6M) in terms of the explanatory variables $\left(X_{1 i}, X_{2 i}, X_{3 i}, X_{4 i}, X_{5 i}\right)$, whose observed values are $\left(x_{1 i}, x_{2 i}, x_{3 i}, x_{4 i}, x_{5 i}\right)$, as well as of the variance $\left(\sigma_{i}^{2}\right)$ of the model error $\left(\epsilon_{i}\right)$, by means of

$$
\begin{aligned}
Y_{i} & =x_{i} \beta+\epsilon_{i}, \\
\sigma_{i}^{2} & =\exp \left(z_{i} \alpha\right),
\end{aligned}
$$

where $x_{i}$ corresponds to the vector of observed values of the explanatory variables denoted as $x_{1 \mathrm{i}}=$ Health $_{i}, x_{2 \mathrm{i}}=\log \left(\operatorname{Risk}_{i}\right), x_{3 \mathrm{i}}=\log \left(\right.$ StdRisk $\left._{i}\right), x_{4 \mathrm{i}}=0$ or 1 (depending if the 
country belongs to the OCDE or not), and $x_{5 \mathrm{i}}=\log \left(\mathrm{GDP}_{i}\right)$ for country $i$. Note that $\beta=\left(\beta_{0}, \beta_{1}, \beta_{2}, \beta_{3}, \beta_{4}, \beta_{5}\right)$ is a vector of regression parameters to be estimated [43,44].

In the formulation given in Equations (2) and (3), $\epsilon_{i}$ corresponds to the model error for observation $i$, which is assumed to be Gaussian distributed, centered on zero, and independent of the other error terms. In contrast, the variance of the error, represented by $\sigma_{i}^{2}$ in (3), is assumed to depend on control variables $z$, where $z_{i}$ corresponds to the vector of explanatory variables for country $i$ and $\alpha$ is a vector of regression parameters to be estimated associated with these variables $z_{i}$.

Maximum likelihood (ML) and generalized least squares (GLS) estimators are compared with the ordinary least squares (OLS) estimator in terms of robustness [45]. If the form of the heteroscedasticity is correctly specified, then the ML and GLS estimators are more efficient statistically than the OLS estimator. Another alternative is using the generalized method of moments (GMM) to estimate the parameters. However, for relatively small samples, the GMM estimators are biased, as mentioned in [46-48].

For this research, the ML estimator is used to perform the data analysis. This is because the estimation by the ML method is more efficient when considering an adequate specification of the model, under the assumption that the error term is Gaussian distributed [49], and the sample is relatively small [50].

\section{Results of the Study and Model Specification}

The first two specifications, named Models 1 and 2, for the response variable $Y$ (Diff3M or Diff6M) consider as explanatory variables: (i) health index; (ii) the logarithm of the average country risk measured through the CDS; and (iii) the logarithm of the standard deviation of the same country risk. These two specifications differ in that the average of the latter was considered when measuring structural change for three and six months of the evolution of the stock market indicators, respectively. The third and fourth specifications, named Models 3 and 4, consider as explanatory variables: (i) health index; (ii) the logarithm of the average country risk; (iii) the logarithm of its standard deviation; and (iv) an indicator of whether or not the country belongs to the OECD group. The fifth and sixth specifications, named Models 5 and 6, include as explanatory variables: (i) health index; (ii) the logarithm of average country risk; (iii) the logarithm of its standard deviation; (iv) an indicator of whether or not the country belongs to the OECD group; and (v) the logarithm of the GDP.

Table 4 reports the results of regression analyses for Models 1-6 of the size of the structural jump. For all cases, the regressions present non-significant parameters. We proceed to analyze the heteroscedasticity effect of the interaction that the different variables in the model can generate. In order to do this, the Breusch-Pagan test is applied to evaluate the heteroscedasticity effect in the regression model. For all models, the null hypothesis of no heteroscedasticity is rejected. Therefore, the phenomenon is modeled considering the effect of the different variables within the variance of the linear model.

Table 5 reports the linear regressions considering the effect of heteroscedasticity. As mentioned, Models 1 and 2 consider health index, logarithm of the average country risk and logarithm of the standard deviation of the same indicator of country risk. Similar to Table 2, they differ in that the structural change measurement was considered as the average of the last three and six months of the evolution of the stock market indicators, respectively. They also incorporate the same variables when modeling the variance. As also mentioned, Models 3 and 4 consider the same explanatory variables of Models 1 and 2, in addition to an indicator of membership to the OECD group. Models 5 and 6 are similar to Models 4 and 5, with the difference that, in the variance modeling, the logarithm of GDP is included. 
Table 4. Parameter estimate and the corresponding standard error (in parenthesis) of the indicated model, as well as statistical indicators of goodness-of-fit $\left(R^{2}\right)$ and significance.

\begin{tabular}{ccccccc}
\hline & Model 1 & Model 2 & Model 3 & Model 4 & Model 5 & Model 6 \\
\hline Variable & (Diff3M) & (Diff6M) & (Diff3M) & (Diff6M) & (Diff3M) & (Diff6M) \\
\hline \multirow{2}{*}{ Health } & 0.0618 & 0.0199 & 0.0312 & 0.0125 & 0.0243 & 0.0064 \\
& $(0.141)$ & $(0.145)$ & $(0.149)$ & $(0.154)$ & $(0.150)$ & $(0.155)$ \\
Log(Risk) & -1.631 & -2.574 & -1.477 & -2.537 & -0.61 & -1.773 \\
& $(3.026)$ & $(3.111)$ & $(3.056)$ & $(3.156)$ & $(3.239)$ & $(3.353)$ \\
Log(StdRisk) & 1.712 & 2.146 & 1.719 & 2.148 & 0.923 & 1.447 \\
& $(2.215)$ & $(2.276)$ & $(2.23)$ & $(2.303)$ & $(2.433)$ & $(2.519)$ \\
OECD & & 1.806 & 0.437 & 1.36 & 0.0449 \\
& & $(2.766)$ & $(2.857)$ & $(2.827)$ & $(2.927)$ \\
Log(GDP) & & & & 0.463 & 0.408 \\
& & & & & $0.556)$ & $(0.576)$ \\
Constant & 18.37 & 25.6 & 17.36 & 25.35 & 12.49 & 21.06 \\
& $(27.09)$ & $(27.85)$ & $(27.32)$ & $(28.22)$ & $(28.04)$ & $(29.03)$ \\
\hline$R^{2}$ & 0.026 & 0.028 & 0.035 & 0.029 & 0.051 & 0.040 \\
F-statistic & 0.376 & 0.415 & 0.385 & 0.31 & 0.444 & 0.345 \\
\hline \multicolumn{7}{c}{ Breusch-Pagan test } \\
\hline$\chi^{2}(1)$ & 4.10 & 3.92 & 7.10 & 4.60 & 5.29 & 3.68 \\
Prob $>\chi^{2}$ & 0.0428 & 0.0476 & 0.0077 & 0.0320 & 0.0214 & 0.0551 \\
\hline
\end{tabular}

${ }^{*} p<0.1,{ }^{* *} p<0.005,{ }^{* * *} p<0.001$.

Table 5. Parameter estimate and standard error of the indicated model considering heteroscedasticity, as well as statistical indicators of goodness-of-fit $\left(R^{2}\right)$ and significance.

\begin{tabular}{|c|c|c|c|c|c|c|}
\hline & Model 1 & Model 2 & Model 3 & Model 4 & Model 5 & Model 6 \\
\hline Variable & (Diff3M) & (Diff6M) & (Diff3M) & (Diff6M) & (Diff3M) & (Diff6M) \\
\hline \multirow{2}{*}{ Health } & 0.038 & 0.0203 & -0.00258 & 0.00543 & $-0.130^{* * *}$ & $-0.130^{* * *}$ \\
\hline & $(0.113)$ & $(0.118)$ & $(0.104)$ & $(0.116)$ & $(0.0190)$ & $(0.0275)$ \\
\hline \multirow{2}{*}{ Log(Risk) } & -1.545 & -2.903 & -1.811 & -3.105 & $-3.628^{* * *}$ & $-5.336^{* * *}$ \\
\hline & $(2.744)$ & (2.946) & $(2.588)$ & $(2.900)$ & $(0.403)$ & $(0.584)$ \\
\hline \multirow{2}{*}{ Log(StdRisk) } & 2.481 & $3.535 *$ & $3.114^{*}$ & $3.900 * *$ & $4.718^{* * *}$ & $6.035^{* * *}$ \\
\hline & (1.877) & (2.010) & (1.718) & $(1.897)$ & $(0.266)$ & $(0.386)$ \\
\hline \multirow{2}{*}{ OECD } & & & 3.367 & 1.924 & $8.157 * *$ & $7.115^{*}$ \\
\hline & & & $(2.325)$ & $(2.47)$ & (3.44) & $(3.796)$ \\
\hline \multirow{2}{*}{ Constant } & 12.33 & 17.32 & 9.765 & 16.69 & $21.20^{* * *}$ & $26.65^{* * *}$ \\
\hline & $(22.9)$ & $(24.7)$ & $(21.14)$ & (24.30) & $(4.992)$ & $(6.518)$ \\
\hline \multicolumn{7}{|c|}{$\log \left(\sigma^{2}\right)$} \\
\hline \multirow{2}{*}{ Health } & -0.018 & -0.0244 & -0.0133 & -0.0165 & 0.00280 & 0.000176 \\
\hline & $(0.0261)$ & $(0.0256)$ & $(0.0261)$ & $(0.0261)$ & $(0.0401)$ & $(0.0441)$ \\
\hline \multirow{2}{*}{ Log(Risk) } & 0.761 & 0.723 & 0.915 & 0.833 & $-1.905^{*}$ & -1.545 \\
\hline & $(0.586)$ & $(0.575)$ & $(0.624)$ & $(0.608)$ & $(1.055)$ & (1.083) \\
\hline \multirow{2}{*}{ Log(StdRisk) } & -0.342 & -0.439 & -0.608 & -0.566 & $1.549 * *$ & 1.291 \\
\hline & $(0.472)$ & $(0.445)$ & $(0.493)$ & $(0.462)$ & $(0.780)$ & $(0.786)$ \\
\hline \multirow{2}{*}{ OECD } & & & $-0.847^{*}$ & -0.627 & $-1.532^{* *}$ & $-1.235^{*}$ \\
\hline & & & $(0.467)$ & $(0.454)$ & $(0.714)$ & $(0.716)$ \\
\hline \multirow{2}{*}{$\log (G D P)$} & & & & & $-2.253^{* * *}$ & $-2.136^{* * *}$ \\
\hline & & & & & $(0.568)$ & $(0.550)$ \\
\hline \multirow{2}{*}{ Constant } & -0.598 & 1.117 & 0.103 & 0.851 & $25.78^{* * *}$ & $23.13^{* *}$ \\
\hline & $(4.978)$ & (4.997) & (4.918) & (4.958) & (8.948) & $(9.030)$ \\
\hline
\end{tabular}

\begin{tabular}{ccccccc}
\hline \multicolumn{7}{c}{ Likelihood Ratio Test for $\log \left(\sigma^{2}\right)=\mathbf{0}$} \\
\hline Prob $>\chi^{2}$ & 0.0570 & 0.1180 & 0.0144 & 0.0824 & 0.0000 & 0.0001 \\
\hline$* p<0.1,{ }^{* *} p<0.005,{ }^{* * *} p<0.001$.
\end{tabular}

${ }^{*} p<0.1,{ }^{* *} p<0.005,{ }^{* * *} p<0.001$. 
Models 5 and 6 present significant parameters of the constant, whether or not they belong to the OECD group, the logarithm of Risk, logarithm of StdRisk, and Health. Models 2,3 and 4 only present a high level of significance in the logarithm of StdRisk.

When analyzing the variance, both Models 5 and 6 indicate significant parameters associated with belonging or not to the OECD group, the logarithm of GDP, and the constant. Furthermore, Model 5 shows a high level of significance in the logarithms of Risk and StdRisk. In addition, note that Models 5 and 6 reject the null hypothesis that the coefficients defining the variance are equal to zero, which suggests that the model should not remove the variables associated with the variance for their adequate specification.

The linear part of the model shows that belonging to the OECD group has a positive impact on the size of the structural breakdown for Models 5 and 6 . Therefore, belonging to the OECD group increases the effect of a structural change because these countries have greater trade openness and then a higher contagion effect on stock markets. In contrast, the significant and negative effects of both the Health and logarithm of the country risk indicate that a country with better institutional and economic conditions is less affected by a massive effect associated with the phenomenon of the pandemic if it had concrete effects on different stock markets.

From Table 4, note that, for Model 1, the mean percentage of loss of wealth of the studied countries increases in 0.0618 when the health index increases in one point. For Models $2-6$, this increase is of $0.0199,0.0312,0.0125,0.0243$, and 0.0064 , respectively. An analogous interpretation is obtained for the values presented in Table 5 corresponding to the explanatory variable health. Tables 4 and 5 differ in considering homoskedasticity or heteroskedastic in the modeling, respectively.

It is worth mentioning that the effect of the health index of Models 5 and 6 has estimated values of its significant parameters. Thus, the health index used for this econometri$\mathrm{cal} /$ statistical modeling determines the capacity of the different countries in responding efficiently when focusing a pandemic effect as viewed from the perspective of stock market developments. However, the contagion effect of stock markets cannot be ruled out as a preponderant factor when analyzing the structural breakdown that has occurred in the world economy.

\section{Discussions, Conclusions, Limitations, and Future Research}

After the recent global financial crises, and during the COVID-19 pandemic in particular-a crisis that is in full swing - appropriate models for describing events that lead to these crises have become quite essential in the areas of finance and risk management. Considering contagion as an equilibrium phenomenon that is generated from the fact that liquidity preference shocks are imperfectly correlated among regions, a financial crisis such as COVID-19 allows the term to capture the attention evaluating the negative financial repercussions for all nations.

Additionally, under normal circumstances, the stock market with its main indexes represents the economy of a country. However, the particular situation of COVID-19 must be considered. In this situation, the stock market does not necessarily represent the economy, because it depends on the contagion effect, the economic conditions, the interrelation among countries, and the development achieved by the companies that make up the main index.

Among the relevant results obtained from the structural breakdown analysis developed in this study, we reported that the estimated date of the structural breakdown for all of the series studied is between the last week of February 2020 and the third week of March 2020. This finding leads to the assumption that a common event was the generator of the global structural change, and we attribute it to the effect of COVID-19. In contrast, countries with better political and economic stability are less affected by the pandemic.

The effect of the health index, as an indicator of the response that countries may have when focusing a health crisis, shows that countries with better health conditions have less impact on the fall in stock indexes during health crisis as that caused by COVID-19. 
We used a regression model with normal and heteroskedastic errors, which assumed that observations taken at different time points are mutually independent [11,12]. This assumption is a limitation of our proposal and could be improved by the search for breakdown points in time series, as done in [51] and literature therein.

The determination of the breaking point of the world financial indexes, based on the analysis of the main indexes considered in the present study, allows us to conclude that this breaking point is attributed to the financial contagion effect of the markets that generates such a break. Therefore, independent of the health index that is determined for a country, the contagion effect is preponderant at crisis times. This allows a prediction of the independent market that affects a country from a health point of view.

This investigation can be improved by considering longer times especially when the virus has ended. This can be possible by analyzing specific geographical areas [52], and by assuming variables and indexes that have recovered faster in the global financial markets to understand the phenomenon from a better perspective.

An important aspect to be further studied is to measure the efficiency and impact of the relevant variables and factors on the stock markets $[53,54]$. Extensions to the multivariate case [55] and the incorporation of temporal [56], spatial [52,57], and quantile regression [57] structures in the modeling, as well as errors-in-variables [58], and PLS regression [44], are also of practical relevance.

The derivation of diagnostic techniques [55] to detect potential influential cases are needed, which are an important tool to be used in all statistical modeling, as well as the use of robust estimation methods [59] are also of empirical interest.

Therefore, the methodology proposed in this investigation promotes new challenges and offers an open door to explore other theoretical and numerical issues. Research on these and other issues are in progress and their findings will be reported in future articles.

Author Contributions: Data curation, H.d.l.F.-M., K.C.-J., and R.R.; formal analysis H.d.1.F.-M., K.C.-J., R.R., and V.L.; investigation, H.d.1.F.-M., K.C.-J., and R.R.; methodology, H.d.1.F.-M., K.C.-J., R.R., and V.L.; writing-original draft, H.d.l.F.-M., K.C.-J., and R.R.; writing-review and editing, V.L. All authors have read and agreed to the published version of the manuscript.

Funding: Research work of $H$. de la Fuente-Mella was partially supported by grant Núcleo de Investigación on Data Analytics/VRIEA/PUCV/039.432/2020 from the Vice-Rectory for Research and Advanced Studies of the Pontifical Catholic University of Valparaíso, Chile; and of V. Leiva was partially supported by FONDECYT 1200525 grant from the National Agency for Research and Development (ANID) of the Chilean government.

Data Availability Statement: The data used to support the findings of this study are available from the corresponding author upon request.

Acknowledgments: The authors thank the Editors and three Referees for their constructive comments on an earlier version of this manuscript, which resulted in this improved version.

Conflicts of Interest: The authors declare no conflict of interest.

\section{References}

1. Chen, M.P.; Lee, C.C.; Lin, Y.H.; Chen, W.Y. Did the SARS Epidemic Weaken the Integration of Asian Stock Markets? Evidence from Smooth Time-Varying Cointegration Analysis. Econ. Res. Ekon. Istraz. 2018, 31, 908-926.

2. Ait-Sahalia, Y.; Cacho-Diaz, J.; Laeven, R.J.A. Modeling Financial Contagion Using Mutually Exciting Jump Processes. J. Financ. Econ. 2015, 117, 585-606. [CrossRef]

3. Keogh-Brown, M.R.; Wren-Lewis, S.; Edmunds, W.J.; Smith, R.D. The Macroeconomic Impact of Pandemic Influenza: Estimates from Models of the United Kingdom, France, Belgium and the Netherlands. Eur. J. Health Econ. 2010, 11, 543-554. [CrossRef] [PubMed]

4. Kostova, D.; Cassell, C.H.; Redd, J.T.; Williams, D.E.; Singh, T.; Martel, L.D.; Bunnell, R.E. Long-Distance Effects of Epidemics: Assessing the Link between the 2014 West Africa Ebola Outbreak and US Exports and Employment. Health Econ. 2019, 28, $1248-1261$. [CrossRef] [PubMed]

5. Tan, S.; Yu-Hung, A.L. Economic Repercussions of Extreme Events for an Island Nation: Case of Singapore. Singap. Econ. Rev. 2016, 61, 19. [CrossRef] 
6. Keogh-Brown, M.R.; Smith, R.D. The economic impact of SARS: How does the reality match the predictions. Health Policy 2008, 88, 110-120. [CrossRef]

7. Sharif, A.; Aloui, C.; Yarovaya, L. Covid-19 Pandemic, Oil Prices, Stock Market, Geopolitical Risk and Policy Uncertainty Nexus in the Us Economy: Fresh Evidence from the Wavelet-Based Approach. Int. Rev. Financ. Anal. 2020, 70, 101496. [CrossRef]

8. Lahmiri, S.; Bekiros, S. Randomness, Informational Entropy, and Volatility Interdependencies among the Major World Markets: The Role of the COVID-19 Pandemic. Entropy 2020, 22, 833. [CrossRef]

9. Rassy, D.; Smith, R.D. The Economic Impact of H1N1 on Mexico's Tourist and Pork Sectors. Health Econ. 2013, 22, 824-834. [CrossRef]

10. Wang, Y.H.; Yang, F.J.; Chen, L.J. An Investor's Perspective on Infectious Diseases and Their Influence on Market Behavior. J. Bus. Econ. Manag. 2013, 14, S112-S127. [CrossRef]

11. De Luca, G.; Loperfido, N. A Skew-in-Mean GARCH Model for Financial Returns. In Skew-Elliptical Distributions and Their Applications: A Journey beyond Normality; CRC/Chapman and Hall: London, UK, 2004; pp. 205-222.

12. De Luca, G.; Loperfido, N. Modelling Multivariate Skewness in Financial Returns: A SGARCH Approach. Eur. J. Financ. 2015, 21, 1113-1131. [CrossRef]

13. Nortey, E.N.N.; Asare, K.; Mettle, F.O. Extreme Value Modelling of Ghana Stock Exchange Index. Springerplus 2015, 4, 17. [CrossRef]

14. Sewraj, D.; Gebka, B.; Anderson, R.D.J. Identifying Contagion: A Unifying Approach. J. Int. Financ. Mark. Inst. Money 2018, 55, 224-240. [CrossRef]

15. Ivanov, I.; Kabaivanov, S.; Bogdanova, B. Stock Market Recovery from the 2008 Financial Crisis: The Differences across Europe. Res. Int. Bus. Financ. 2016, 37, 360-374. [CrossRef]

16. Imran, M.; Wu, M.Y.; Gu, S.B.; Saud, S.; Abbas, M. Influence of Economic and Non-Economic Factors on Firm Level Equity Premium: Evidence from Pakistan. Econ. Bull. 2019, 39, 1774.

17. Su, X.F. Dynamic Behaviors and Contributing Factors of Volatility Spillovers across G7 Stock Markets. N. Am. J. Econ. Financ. 2020, 53, 16. [CrossRef]

18. Hajizadeh, E.; Seifi, A.; Zarandi, M.N.F.; Turksen, I.B. A Hybrid Modeling Approach for Forecasting the Volatility of S\&P 500 Index Return. Expert Syst. Appl. 2012, 39, 431-436.

19. Vera Leyton, M. Contagio del Mercado Accionario: Casos de Colombia, Mexico, Peru, Chile y Argentina. Dimens. Empresarial 2020, 18, 1-32.

20. Forbes, K.; Rigobon, R. No Contagion, Only Interdependence: Measuring Stock Market Comovements. J. Financ. 2002, 57, $2223-2261$. [CrossRef]

21. Feng, L.; Zhang, X.; Liu, B. Multivariate Tests of Independence and Their Application in Correlation Analysis between Financial Markets. J. Multivar. Anal. 2020, 179, 104652. [CrossRef]

22. Kaminsky, G.L.; Reinhart, C.M. On Crises, Contagion, and Confusion. J. Int. Econ. 2000, 51, 145-168. [CrossRef]

23. Blommestein, H.; Eijffinger, S.; Qian, Z.X. Regime-Dependent Determinants of Euro Area Sovereign CDS Spreads. J. Financ. Stab. 2016, 22, 10-21. [CrossRef]

24. Galariotis, E.C.; Makrichoriti, P.; Spyrou, S. Sovereign Cds Spread Determinants and Spill-over Effects during Financial Crisis: A Panel Var Approach. J. Financ. Stab. 2016, 26, 62-77. [CrossRef]

25. Allen, F.; Gale, D. Financial Contagion. J. Political Econ. 2000, 108, 1-33. [CrossRef]

26. Anastasopoulos, A. Testing for Financial Contagion: New Evidence from the Greek Crisis and Yuan Devaluation. Res. Int. Bus. Financ. 2018, 45, 499-511. [CrossRef]

27. Jin, X.Y.; An, X.M. Global Financial Crisis and Emerging Stock Market Contagion: A Volatility Impulse Response Function Approach. Res. Int. Bus. Financ. 2016, 36, 179-195. [CrossRef]

28. Karanasos, M.; Yfanti, S.; Karoglou, M. Multivariate Fiaparch Modelling of Financial Markets with Dynamic Correlations in Times of Crisis. Int. Rev. Financ. Anal. 2016, 45, 332-349. [CrossRef]

29. Zhu, Y.G.; Yang, F.; Ye, W.Y. Financial Contagion Behavior Analysis Based on Complex Network Approach. Ann. Oper. Res. 2018, 268, 93-111. [CrossRef]

30. Kokholm, T. Pricing and Hedging of Derivatives in Contagious Markets. J. Bank. Financ. 2016, 66, 19-34. [CrossRef]

31. Oikonomikou, L.E. Modeling Financial Market Volatility in Transition Markets: A Multivariate Case. Res. Int. Bus. Financ. 2018, 45, 307-322. [CrossRef]

32. Lewis, V.; Roth, M. The Financial Market Effects of the ECB's Asset Purchase Programs. J. Financ. Stab. 2019, 43, 40-52. [CrossRef]

33. Ahundjanov, B.B.; Akhundjanov, S.B.; Okhunjanov, B.B. Information Search and Financial Markets under COVID-19. Entropy 2020, 22, 791. [CrossRef] [PubMed]

34. Drożdż, S.; Kwapień, J.; Oświęcimka, P.; Stanisz, T.; Waţorek, M. Complexity in Economic and Social Systems: Cryptocurrency Market at around COVID-19. Entropy 2020, 22, 1043. [CrossRef]

35. Mounier-Jack, S.; Coker, R.J. How prepared is Europe for pandemic influenza? Analysis of national plans. Lancet 2006, 367, 1405-1411. [CrossRef]

36. Umaña-Hermosilla, B.; De la Fuente-Mella, H.; Elórtegui-Gómez, C.; Fonseca-Fuentes, M. Multinomial Logistic Regression to Estimate and Predict the Perceptions of Individuals and Companies in the Face of the COVID-19 Pandemic in the Nuble Region, Chile. Sustainability 2020, 12, 9553. [CrossRef] 
37. Global Health Security Index: Building Collective Action and Accountability. Nuclear Threat Initiative and Johns Hopkins School of Public Health. 2019. Available online: https:/ /www.ghsindex.org/wp-content/uploads/2019/10/2019-Global-HealthSecurity-Index.pdf (accessed on 23 September 2020).

38. Pan, J. and K.J. Singleton. Default and Recovery Implicit in the Term Structure of Sovereign CDS Spreads. J. Financ. 2008, 63, 2345-2384. [CrossRef]

39. Fontana, A.; Scheicher, M. An Analysis of Euro Area Sovereign Cds and Their Relation with Government Bonds. J. Bank. Financ. 2016, 62, 126-140. [CrossRef]

40. Quandt, R. Tests of the hypothesis that a linear regression system obeys two separate regimes. J. Am. Stat. Assoc. 1960, 55, 324-330. [CrossRef]

41. Andrews, D.W.K. Tests for Parameter Instability and Structural Change with Unknown Change Point. Econometrica 2003, 71, 395-397. [CrossRef]

42. Paz, A.; De la Fuente-Mella, H.; Singh, A.; Conover, R.; Monteiro, H. Highway expenditures and associated customer satisfaction: A case study. Math. Probl. Eng. 2016, 2016, 4630492. [CrossRef]

43. Coughenour, C.; De la Fuente-Mella, H.; Paz, A. Analysis of self-reported walking for transit in a sprawling urban metropolitan area in the western US. Sustainability 2019, 852, 2-16.

44. Huerta, M.; Leiva, V.; Liu, S.; Rodriguez, M.; Villegas, D. On a partial least squares regression model for asymmetric data with a chemical application in mining. Chemom. Intell. Lab. Syst. 2019, 190, 55-68. [CrossRef]

45. De la Fuente-Mella, H.; Vallina, A.; Solis, R. Stochastic analysis of the economic growth of OECD countries. Econ. Res. Ekon. Istraž. 2020, 33, 2189-2202. [CrossRef]

46. Greene, W.H. Econometric Analysis; Pearson: New York, NY, USA, 2018.

47. Altonji, J.G.; Segal, L.M. Small-sample bias in GMM estimation of covariance structures. J. Bus. Econ. Stat. 1996, 14, 353-366.

48. Clark, T.E. Small-Sample Properties of Estimators of Nonlinear Models of Covariance Structure. J. Bus. Econ. Stat. 1996, 14, 367-373.

49. Santos, L.A.; Barrios, E.B. Small sample estimation in dynamic panel data models: A simulation study. Am. Open J. Stat. 2011, 1, 58-73. [CrossRef]

50. Harvey, A. Estimating regression models with multiplicative heteroscedasticity. Econom. J. Econom. Soc. 1976, 461-465. [CrossRef]

51. Hart, R.; Clark, D. Does size matter? Exploring the small sample properties of maximum likelihood estimation. In Proceedings of the Annual Meeting of the Midwest Political Science Association, Chicago, IL, USA, 20-22 April 1999.

52. Vallina-Hernandez, A.M.; de la Fuente-Mella, H.; Fuentes-Solís, R. International Trade and Innovation: Delving in Latin American Commerce. Acad. Rev. Latinoam. Adm. 2020, 33, 535-547. [CrossRef]

53. Wang, T.; Samworth, R.J. High-dimensional Changepoint Estimation via Sparse Projection. arXiv 2016, arXiv:1606.06246.

54. De la Fuente-Mella, H.; Rojas Fuentes, J.L.; Leiva, V. Econometric Modeling of Productivity and Technical Efficiency in the Chilean Manufacturing Industry. Comput. Ind. Eng. 2020, 139, 105793. [CrossRef]

55. Díaz-García, J.A.; Galea, M.; Leiva, V. Influence Diagnostics for Multivariate Elliptic Regression Linear Models. Commun. Stat. Theory Methods 2003, 32, 625-641. [CrossRef]

56. Leiva, V.; Saulo, H.; Souza, R.; Aykroyd, R.G.; Vila, R. A New BISARMA Time Series Model for Forecasting Mortality using Weather and Particulate Matter Data. J. Forecast. 2020. [CrossRef]

57. Sanchez, L.; Leiva, V.; Galea, M.; Saulo, H. Birnbaum-Saunders Quantile Regression Models with Application to Spatial Data. Mathematics 2020, 8, 1000. [CrossRef]

58. Carrasco, J.M.F.; Figueroa-Zúñiga, J.I.; Leiva, V.; Riquelme, M.; Aykroyd, R.G. An Errors-in-Variables Model based on the Birnbaum-Saunders Distribution and its Diagnostics with an Application to Earthquake Data. Stoch. Environ. Res. Risk Assess. 2020, 34, 369-380. [CrossRef]

59. Velasco, H.; Laniado, H.; Toro, M.; Leiva, V.; Lio, Y. Robust Three-step Regression based on Comedian and its Performance in Cell-wise and Case-wise Outliers. Mathematics 2020, 8, 1259. [CrossRef] 